\title{
An Scéalaí: autonomous learners harnessing speech and language technologies
}

\author{
Neasa Ní Chiaráin, Ailbhe Ní Chasaide \\ Trinity College, Dublin \\ neasa.nichiarainetcd.ie, anichsidetcd.ie
}

\begin{abstract}
This paper presents an autonomous language learning platform which has speech and language technology at its core. An Scéalai ('the Storyteller') is a web-based interactive iCALL system that allows learners to compose their own text and correct it by listening to the text spoken with synthetic voices (aural proofing) and by responding to NLP prompts that detect errors. All learner interactions are logged and monitored, allowing researchers to observe the learning processes.

A pilot study by 14 learners of Irish in the US was conducted to explore the efficacy of the corrective mechanisms currently implemented in the platform.

The results of the pilot study indicate that both mechanisms currently on offer were effective in the development of writing skills but work in rather different ways. Aural proofing appears to generate an immediate corrective response which indicates that it is serving both to develop awareness of specific phonological contrasts as well as basic phonic rules of the language. In the case of the NLP prompts, corrections were also made, although the data suggest that this is a slower process and that learners may, at least initially, merely be satisfying the system's prompts rather than discovering the grammatical basis of the correction.
\end{abstract}

The pilot has been useful in pointing towards future directions for platform development that can take the needs of this type of adult autonomous learner into account.

Index Terms: iCALL platform, text-to-speech synthesis, NLP, corrective feedback

\section{Introduction}

\subsubsection{An Scéalaí: a new iCALL platform for Irish}

An Scéalai ('the Storyteller') is an iCALL platform for Irish, which is currently under development. At its core are the speech and language technologies that are currently being built for the language. An Scéalai is intended as a potentially autonomous language learning platform where learners are given the opportunity to practice the four basic communication skills of writing, listening, reading and speaking. The overarching aim is to integrate these skills. The use of synthetic speech is important: although TTS systems are relatively little used in language teaching applications, in many cases they may present the only viable way to put the spoken language centre stage in the development of language skills in an autonomous learning context. An Scéalai provides a mechanism for 'virtual immersion' that links learners' spontaneous productive skills and L2 fluency [1, p.55]. The system's web-based user interface is shown in Figure 1. The concept and the name of the platform draw on the strong tradition of storytellers in Irish culture, which in pre-television age was a main form of entertainment and of transmitting wisdom in rural Ireland. The hope is that this electronic version will grow to nurture future storytellers in a way that marries an old tradition with the digital age. In its present configuration An Scéalai is very much a language learning tool. However, the early focus on writing your own story will, we hope, evolve to provide a foundation for creative writing in the future, supported by the 'wisdom' that can be incorporated through 'intelligent' speech and language technologies.

In the current version of this platform, the learner writes content and proceeds to correct it using two feedback modalities. The first entails NLP prompts for errors. These are identified by the use of an open source grammar checker for Irish, An Gramadóir [2], which at the press of a button scans the text and signals errors and error types. The second modality entails listening to a native speaker rendition of the text, spoken by the one of the synthetic voices of the ABAIR text-to-speech system for Irish [3]. This is essentially an aural proofing tool.

All learner interactions are logged and accessible for research. As such, this platform aims to provide "fully monitored conditions for conducting empirical research on L2 interaction" as proposed by Hegelheimer \& Chapelle [4]. The researchers are also the platform designers and as such aim for a controllable learning environment that can be adapted over time towards optimal conditions for learning (including learner modeling, feedback, adaptivity and featuring eventually additional personalization and motivational support).

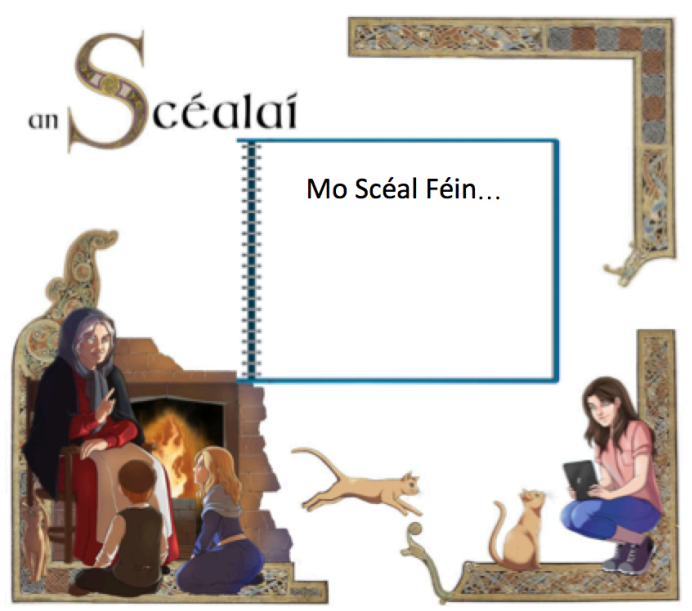

Figure 1: An Scéalai ('Storyteller') learner webpage.

\subsubsection{The ABAIR initiative}

It should be noted that this building of educational applications is taking place as part of the wider ABAIR research initiative at the Phonetics and Speech Lab., Trinity 
College Dublin. The ABAIR initiative addresses three central elements of speech technology development for Irish (Gaelic) - (1) the provision of basic underpinning linguistic-phonetic resources, (2) the building of core speech technologies, and (3) the development of technology applications, which exploit both the technologies and the linguistic resources. These linkages are crucial as the backdrop for the current educational application development in that there is access to each module of the core speech and language technology, and these can be adapted as necessary following feedback from user testing. This paper presents a pilot study recently conducted with learners of Irish in the US, both to test the effectiveness of the corrective feedback offered in the platform and to gain insights that would lead to further refinements.

\subsubsection{The Irish Language Context}

Speech-enabled autonomous learning platforms are particularly important in the context of a minority language such as Irish. Although there are learners of Irish around the globe, they frequently have little access to speakers of the language. This is highlighted in the present pilot as the learners are based in the US.

The pronunciation and writing of Irish presents specific challenges. To begin with the sound system is complex and very different from English, for example in the contrast of velarized and palatalized consonants (e.g. leon, / $/ \mathbf{j} \mathrm{o}$ : n $\mathrm{n} /$, 'lion' and lón /Ir o: ñy/ 'lunch'). This is compounded by a complex writing system, where the mappings of letter to sound, the phonic rules, are anything but transparent. Consequently, learning to write the language can be daunting, particularly if the learner cannot hear how the written text is pronounced.

\section{Theoretical Background}

This platform falls squarely within the task-based language learning (TBLL) approach which implicitly promotes an integrated view of language, even when particular skills such as grammatical structure or writing/spelling are being targeted. From the outset the users' needs are paramount and the aim is specifically to afford the possibility of user-driven autonomous learning in the setting of goals, which in this case entails user reflections on their own language learning journey.

The corrective feedback which is delivered through aural and written modalities is intended to encourage learners' noticing [5], so that they become aware of underlying grammatical and phonological processes of the language, and of the gap between their own productions and the patterns of the target language. The platform also empowers students to revise and proofread their own work and, as mentioned earlier, places the spoken language at the centre of all learning activities.

\section{Design}

An Scéalai is configured with an integrated TTS capacity of the ABAIR system [6]. This TTS system allows a choice of the three main dialects, including both male and female 'speakers'. Following registration and the initial profile building, the user chooses their preferred dialect/speaker and is invited to write their own story or other content.

The platform guides the learner through a four-step process, illustrated in Figure 2:

1. Write your story
2. Read and correct your writing using NLP prompts

3. Listen and correct your writing using ABAIR TTS

4. Speak your text by reading it aloud

Once the writing has begun (Step 1), intelligent self-correction is promoted through the subsequent steps: in Step 2, the learner is prompted to correct their text by NLP prompts. In Step 3 the learner listens carefully using ABAIR TTS to pick up on possible errors by ear. Note that these are not necessarily consecutive steps: the NLP checker and TTS are available at all times to the learner and they can access them in any order they like and use them as many times as they like. Step 4 allows the learner to record their own voice reading out their own corrected text. This is generally done when the learner is happy their piece is completed. The intention is that learners should compare their own production with that of the synthetic 'native speaker'. Through reiteration the goal of this last step is to train the learner on direct imitation of native speaker speech. The recording feature was not focused on in this pilot study.

All learner attempts are logged. This has two purposes: it allows researchers access to the process of self-correction as well as to the items corrected. It also potentially allows teachers to track learner progress, provide feedback and tailor their classes accordingly. It is also intended as An Scéalai is rolled out on a larger scale that teachers will provide feedback to the program designers, which can help the further development of the platform.

\section{An Scéalaí}
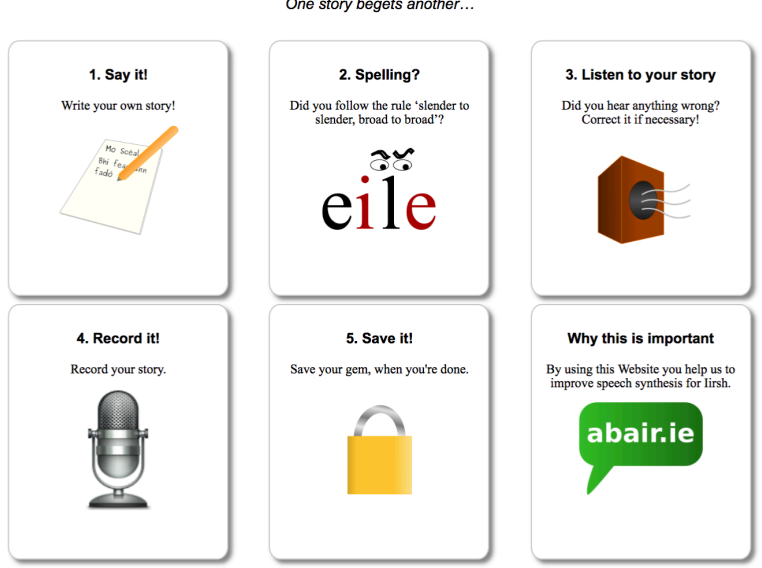

Figure 2: An Scéalai features and their ordering

More detail on the individual steps is provided in Ní Chiaráin and Ní Chasaide [7]. In the following pilot study we focus particularly on Steps 2 and 3.

\section{Pilot Study: Learners of Irish in the US}

The pilot study reported here was conducted with a group of adult learners in the US. The aim was to ascertain whether and to what extent the two processes of self-correction (Step 2 NLP prompting based primarily on a grammar checker or Step 3 aural feedback using TTS) were effective in improving learners' written production.

Participants were third level students in three universities who are taking Irish classes as an extracurricular subject. Their level was estimated to be A2 in the CEFR framework. A key goal was to examine the capacity of An Scéalai to make 
learners aware of errors in their written productions to enhance their conscious awareness of the issue and their ability to selfcorrect.

The writing task the learners were given was unstructured - they were asked to keep a reflective diary on their language learning journey over a 12 week period. Researchers created YouTube videos on how to use the system for tutors and learners. Tutors encouraged learners to use An Scéalai but self-correction was system- rather than tutor-led. As mentioned above, it is intended that the platform will incorporate mechanisms that will allow them to intervene with feedback to learners.

21 participants undertook this study, 14 of whom continued with it. Those who did not continue were all in the same class group and although they registered they did not follow the videos and their tutor did not follow up on their use of the system. Of the 14, all but one used the NLP tools for self-correction. 10 of the 14 used the TTS voices.

At the end of the 12 weeks students filled in a debriefing questionnaire which elicited their impressions of the system, both positive and negative. Tutors were also asked for their feedback. In the following we report results in terms of a qualitative look at the error types and error correction processes used by the learners. Feedback from learners and tutors is also discussed.

\section{Results}

\subsection{Analysis of Error Corrections by Learners}

Examination of learner logs indicate that two different types of errors tend to be corrected using the modalities of Steps 2 and 3. There are also indicators that the learning process is quite different in each case.

\subsubsection{NLP prompt-based proofing (Step 2)}

The errors that were successfully corrected using prompts from a grammar checker were spelling errors reflecting morphological-grammatical and simple spelling errors. Some examples include the following:

- number agreement, where the article and noun did not match (*an dathanna corrected to na dathanna, "the colours', where the article an / $n a$ 'the' is required to have a singular / plural form).

- spelling errors, such as the lack of the acute accent $(f a d a)$, which marks long vowels in Irish. Once such correction was the addition of the frequently absent acute accent in the word breá 'fine'. The grammar checker identifies these as errors as there is no word brea without the acute accent in Irish.

- lenition of initial consonants in specific grammatical contexts, such as after the possessive pronoun mo 'my'. For example, mo theaghlach 'my family' was written as *mo teaglach. In this particular instance the learner tried to correct repeatedly using different strategies. The prompt provided by the grammar checker LENITION MISSING was not enough and after five attempts the learner abandoned the wording and substituted with sinn 'us'. Although on face value this looks like a failure to correct, it becomes clear that some weeks later subsequent prompts of LENITION MISSING yielded appropriate correction. This indicates that the learner has become aware of lenition as a grammatical process and is able to correct the written forms appropriately.

\subsubsection{TTS-based aural proofing (Step 3)}

It was striking that the errors corrected through aural proofing involved a much more immediate process. This mechanism was effective in examples such as the following:

- the correction of absent acute marking on long vowels, as was mentioned above. Although the grammar checker should, in principle, pick up on many of these, and one might expect them to be corrected in Stage 2, this was often not the case and the aural feedback appears to be particularly effective. Note also that there are also many cases where forms with and without the acute accent are valid words of the language (sean 'old', Seán 'John', séan 'deny'; ait 'odd', áit 'place'; fear 'man', féar 'grass'; briste 'broken', bríste 'trousers'; leacht 'liquid', léacht 'lecture').

- liaison, or connected speech processes, where the first of two vowels abutting across a word boundary is elided (*mo árasán -> m'árasán 'my apartment').

- complex corrections at a phrasal level. For example *d'fhéach mé an cluiche peile -> d'fhéach mé ar an gcluiche peile 'I watched (looked at) the football match'. This example illustrates a dual correction. Firstly, the missing preposition 'at' is supplied. This preposition triggers a mutation $/ \mathrm{k} /->/ \mathrm{g} /$ in the noun's initial consonant so that cluiche 'game' is realized as gcluiche.

\subsection{Feedback}

\subsubsection{Feedback from learners' questionnaires}

The majority of comments reflected a high degree of satisfaction with learners mentioning it was particularly useful for additional work at home - which was one of the envisaged goals. Further feedback provided useful indicators as to how the system might be improved. Students mentioned that it would help if they could choose different speeds in the speech output, as it was sometimes too fast for their level of comprehension. Other useful suggestions pertained to the design and usability of the webpage. The grammar checker (which incorporates a spell checker) was also commented upon, particularly insofar as it did not catch all the errors. Learners also pointed out that they would have appreciated a facility that would allow them to keep track of their progress.

\subsubsection{Feedback from tutors}

Feedback from tutors was very positive. They reported that improvements in writing skills during the period were appreciable and were interested in continuing to use the platform in further testing. They particularly liked that it encouraged autonomous learning by the students and a creative approach with language production. As with learners, tutors also pointed to the need for a feedback loop where both teachers and learners could see previous efforts and track progress. Tutors also pointed out that they would appreciate a mechanism to allow them to give students further feedback and guidance via the platform. 


\section{Discussion}

Overall it appears that this platform does contribute to improvements in learners' production, insofar as learners' written pieces were improved following its use. It also seems that the two correction mechanisms (the aural and the textbased prompting) work in rather different ways.

\subsubsection{Aural proofing}

The aural feedback appears to work in a very direct and relatively immediate fashion. There is no prompting, rather the learner is forced to notice and become more consciously aware of errors which have audible consequences. It is here that one finds an integration of skills, in that both phonological awareness (of a contrast such as the long/short vowels) and phonic awareness (how the contrast is realized in writing) are simultaneously trained. When learners correct ait /a/ 'odd' -> áit /a:/ 'place', for example, they are acquiring not just a spelling rule but a basic phonic rule of the language. Conscious noticing is a valuable skill in all aspects of language learning and is promoted in this platform by the inclusion of TTS voices

However, it must be born in mind that the aural proofing requires of the learner a level of phonological awareness as well as a certain proficiency level in order to be useful. The vowel length contrast illustrated here is accessible to an English-speaker's ear, but for other contrasts of Irish (such as the opposition of velarized and palatalized consonants, as in bád $/ b^{8}$ a d $\mathbf{y} /$, báid $/ b^{8}$ a: $\mathbf{d} \mathrm{j} /$ ), a prior ear training would almost certainly be needed. All in all, the aural proofing approach has the distinct advantage that it can serve as a mechanism for noticing and reinforcing phonological awareness.

\subsubsection{NLP prompts}

The use of NLP prompts emerged also as an effective correction tool but there are indicators that the learners may require numerous iterations to come up with a corrected form. Furthermore, the evidence from log files suggests that the reason for a specific correction remains opaque and that there is considerable trial and error involved to come up with a correct form. To this extent, the feedback from the grammar checker as it currently stands is not pedagogically optimal. Ideally, the learner would benefit from feedback and direct guidance that explains how/why something is incorrect and the rule that can lead to correct written forms. The value of automated corrective feedback is an area of current debate see, for example, [8] who raise similar questions. Of course, the corrective feedback offered in this platform in many ways mirrors the text-based feedback traditionally provided by teachers (in the form of notes in margins). The effectiveness of this form of feedback is an open question whether it is delivered by computer or by teacher.

\subsubsection{Consequences for Platform Design}

This pilot prompts future design innovations. 4 of the 14 participants did not in fact use the TTS as part of the writing process but remained locked into Steps 1 and 2. As a primary aim of the platform is to integrate the 4 skills, and to make the spoken language integral to all language learning activities, we propose in future iterations to make the listening a necessary and attractive part of the exercise, rather than an optional extra.
The feedback comments of learners and tutors also guide further development of the platform. The need for controlling the speed to suit learners at different levels, the need for a feedback mechanism to allow both learners to track progress and to allow additional tutor feedback are features that will be incorporated.

On the whole, the pilot study, although quite limited, confirms the usefulness of the platform in the development of writing skills, and provides useful feedback for the next stage of the development.

\section{Conclusions}

This pilot confirms that the platform does offer an ideal solution for targeted corrective feedback.

Both the aural feedback and the NLP prompts together contributed to improved writing skills. In the case of the aural feedback, there is clear evidence that learners are noticing aspects of the language phonology and phonics. To this extent, the system provides subliminal phonics training.

The integration of TTS is valuable in increasing learners' exposure to native speaker models of the language. This was particularly important for this cohort of foreign learners where opportunities to interact with native speakers are very limited.

The NLP prompts provided by the grammar checker also lead to learning about morphophonological processes, as was illustrated with the LENITION MISSING example in Section 5.1.1 above. In these cases it was clear that the learning occurred over a number of weeks and required considerable reiteration.

As pointed out by teachers the platform and corrective mechanisms encouraged autonomy and creativity among learners.

Overall the indicators are that this platform promises to be a powerful tool, both as a standalone autonomous facility and as a complement to classroom activity. The strength of the system for the learner is not only the opportunities for corrective feedback but also for the integration of skills. As all the data is logged, the platform is also useful to the researcher in providing valuable insight into the processes of learning and how these may differ depending on the modality of corrective feedback.

Future design features prompted by this pilot study include the inclusion of feedback mechanisms to learners and the possibility of tutor-learner communication. An innovation also deemed necessary by the learners is the possibility of varying the speed of speech output to accommodate learners at different levels. This requires collaboration with the ABAIR synthesis building team. This is not a trivial task as it may require adjustments in the operation of postlexical rules in the synthesis system, given that at very slow speeds citation forms will be needed rather than the more naturally coarticulated forms of synthesis when running at normal speed. This latter point highlights the advantages that accrue when pedagogical applications and core technology development can be collocated.

\section{Acknowledgements}

This work has been funded by An Roinn Cultúir, Oidhreachta agus Gaeltachta and the Straitéis Fiche Bliain don Ghaeilge. The support of An Chomhairle um Oideachas Gaeltachta agus Gaelscolaíochta is also gratefully acknowledged. 


\section{References}

[1] H. Muranoi, "Output practice in the L2 classroom," in R.M. DeKeyser (Ed.), Practice in a second language: Perspectives from applied linguistics and cognitive psychology, Cambridge; New York: Cambridge University Press, pp.51-84, 2007.

[2] K. Scannell. "An Gramadóir". Available at: http://borel.slu.edu/gramadoir, 2005.

[3] ABAIR - the Irish language synthesizer. Available at: www.abair.ie, 2019

[4] V. Hegelheimer and C. A. Chapelle, "Methodological Issues in Research on Learner-Computer Interactions in CALL," Language Learning \& Technology, vol. 4, no. 1, pp. 41-59, 2000

[5] R. Schmidt, "Attention, awareness, and individual differences in language learning”. In W. M. Chan, S. Chi, K. N. Cin, J. Istanto, M. Nagami, J.W. Sew, T. Suthiwan, \& I. Walker, Proceedings of CLaSIC 2010, Singapore, December 2-4. Singapore: National University of Singapore, Centre for Language Studies, pp. 721737, 2010.

[6] A. Ní Chasaide, N. Ní Chiaráin, C. Wendler, H. Berthelsen, A Murphy and C. Gobl, "The ABAIR initiative: Bringing Spoken Irish into the Digital Space" in INTERSPEECH $2017-18^{\text {th }}$ Annual Conference of the International Speech Communication Association, August 20-24, Stockholm, Sweden, Proceedings, 2017.

[7] N. Ní Chiaráin and A. Ní Chasaide, "An Scéalaí: synthetic voices for autonomous learning" in P. Taalas, J. Jalkanen, L. Bradley \& S. Thouësny (Eds), Future-proof CALL: language learning as exploration and encounters - short papers from EUROCALL 2018. Research-publishing.net, pp. 230-235, 2018.

[8] M. Stevenson and A. Phakiti, "The Effects of ComputerGenerated Feedback on the Quality of Writing" Assessing Writing, vol.19, no. 1, pp. 51-65, 2014. 